\title{
An empirical study on the application of memetics to the teaching of college English writing
}

\author{
Zeyun Huang* \\ Department of Foreign Languages, Wuhan University of Technology Huaxia College, Wuhan, Hubei, China
}

\begin{abstract}
Memes, the replicator of culture and information, and basic unit of culture, are copied, spread, transmitted and finally survives through imitation among vectors. The replication and transmission of memes have some resemblance to the process of second language acquisition. This paper examines the influence of language memes on the development of Chinese college students' English writing proficiency through an empirical study. The study reveals that students instructed by the framework of teaching writing with memetics obtain an obvious improvement in their overall writing proficiency, compared with those who are instructed by the traditional method, that students' awareness of using memes is greatly enhanced, and that language memes are significantly correlated to the students' performance in the post-test writing. Singular language memes can be easily transmitted; memetic genotype prevails in EFL learners' essay writing.
\end{abstract}

Keywords: memes; college English writing; imitation; mimetic life cycle

\section{MEMES}

A gene is a unit of heredity and a replicator in biology, and it is ultimately their competition that drives the biological evolution. Does there exist a similar replicator in human culture? Dawkins proposes "meme" in his best-selling book The Selfish Gene [1] by analogy. Dawkins shortens the Greek word "Mimeme" which means imitation to "meme". Examples of memes are "tunes, ideas, catch-phrases, clothes fashions, and ways of making pots or of building arches" [1]. But later, Dawkins says that a meme is a unit of information which can "propagate themselves from brain to brain, from brain to book, from book to brain, from brain to computer, from computer to computer"'[2]. In Blackmore's view, memes are ideas, habits, skills, stories, songs or any other kind of information that is copied from person to person[3], and "any information that is copied in an evolutionary process (i.e. with variation and selection)"[4]. Briefly, memes, the replicator of culture and basic unit of culture, are copied, spread, transmitted and finally survives through imitation among vectors.

The power behind the idea of memes is of theoreti-

*Corresponding author: 625940273@qq.com cal significance, it illustrates how human information is copied, spread and transmitted [5]. Memes and languages are coexisting and indispensable [6]. For one thing, language is a memeplex. Language is the carrier of memes and its function is to spread memes. For another, memes benefit the development of language, and at the same time they benefit themselves in the process of replicating and transmitting. Mimetically, language memes reveal, from a new perspective, the law of language replication and language transmission, which serves as a guideline for learning and applying language effectively. Professor He Ziran argues that memes is of significance to language teaching, especially to foreign language teaching [7]. His idea shreds a new light into language teaching.

Human is gifted with imitation. Gabriel Tarde argues that the whole history of human being is a history of imitation, and it is imitation that enables an individual's inventions to become the whole human's common wealth. "Society is imitation" [8], what makes human beings unique is the ability to imitate. Imitation is the fundamental concept of memetics. According to Blackmore, only human beings are capable of true imitation, “...it is imitation that gives rise to big brains and language, and it is imitation that makes culture possible" [4]. So, the essence of meme replication and transmission is imitation. 
Imitation comes in many ways. However, imitation here does not mean merely copying or repeating of the original memes from content to form. Imitation does not mean "cloning", and creation originates from imitation [3].So does the process of learning foreign languages. When we learn a second language, we have to read, listen, speak and write. All of those are the spread and transmission of second language elements from others to us or vice versa. This is a process of imitation from mimetic point of view.

\section{LITERATURE REVIEW}

\subsection{Mimetic study abroad}

The development of memetics is just like the spread of meme. Since the moment it was coined and proposed by Dawkins, the term "meme" has been employed under different meanings with a variety of disciplines. Presently, memetic study concentrates on two main angles of view: firstly, mimetic researches involving the study of culture, sociology, philosophy and so on. Secondly, mimetic researches involving linguistics [9]. Scholars who are for memetics fall into four groups: 1) they understand a meme, from the view of information processing, 2) from the point of view of thought contagion, 3) from the point of view of cultural evolution, and from semiotic point of view [10].

In 1999, with the publication of The Meme Machine [3], Susan Blackmore raised another upsurge in the field of mimetic study. Her study is a landmark on the way of mimetic development.

\subsection{Mimetic study in China}

Mimetic theory is new in the Chinese academic world. Memetics was introduced into China in 1980's and no research has attracted much attention until 2002. Mimetic study at home centers on the combination of memetics and linguistics as well as applied linguistics. Scholars dwelling on this field fall into three categories: 1) on memetics and translation/ culture, 2) on memetics and language/language teaching, 3) the debate on memeics. Most of them belong to the first and second type [10].

College English writing has always been ineffective in China, currently, the most prevailing question is "scarcity of content" [11] and "product-driven writing"[12]. Approaches, such as the Product Approach, the Process Approach, and Length Approach have been adopted to improve the efficiency of college students' writing. None of these is satisfactory. The combination of memetics and the Process Approach will provide a new perspective to the teaching of college English writing, some qualitative studies have been conducted in China [13] [14].

\section{THE STUDY}

\subsection{Research questions}

This paper examines the influence of language memes on the development of Chinese college students' English writing proficiency and the way of language learners spreading language memes through an empirical study which adopts the framework presented by Yang [14]. This thesis will address to the following two questions:

1. What is the overall effect of memetic language writing?

2. Which kind of memes can be easily imitated and transmitted by second language learners, singular memes or memeplexes? Which way of mimetic transmissions can infect EFL learners more effectively, genotype or phenotype?

\subsection{Subjects}

The participants were some college freshmen of Grade 2013 in the Department of Computer Science of Wuhan University of Technology Hua Xia College. Two classes were chosen, by drawing lots, Class 1 was chosen as the control class, while Class 2 was the experimental class. There were fifty-two students in each of the class. They were not told they were getting involved in a teaching experiment. Their College English was given by one teacher, the author of this thesis.

\subsection{Instruments and data collection}

The researcher employed two instruments to collect data, pre-test and post-test. Firstly, two raters with sufficient experiences graded the participants' compositions according to Global Scoring Schema in CET-4 separately. Secondly, the researcher identified language memes employed by experimental class in their compositions, and categorized them.

\subsection{Procedures}

The experiment was conducted in three steps: pre-test, treatment and post-test.

\section{Pre-test and post-test}

All the participants were asked to write a composition of about 120 words within 30 minutes in class, and the topics were from College English Test (Band-Four). Altogether 208 articles were collected.

\section{Treatment}

During the experiment (12 weeks in total), the subjects were assigned six tasks. All the tasks were required to finish within 30 minutes in class.

Different training methods were employed by the same teacher in the two classes. The traditional teaching method was employed in the control class. The students were asked to write a composition after the 
topics presented and then handed in their essays, and the researcher graded their compositions and returned them their writings with some feedback on the lexical and grammar mistakes. Whereas, in the experimental class, memetics was applied to the teaching of college English writing in the combination with the Process Approach [15]. The learners went through four steps in producing a piece of writing: input, memorization, output and interaction [16]. Sufficient input was done in class first, and language memes were highlighted. Then memorization came in the second place, the students were required to recite those language memes. Output which refers to braining storming, planning, communicating and drafting came in the third place. Interaction consisting of four steps will be illustrated in Stage Four.

\section{A whole life cycle of memes}

In this part, I'll dwell on how to apply memetics to the teaching of College English writing. The central point was to complete the whole life cycle of memes in teaching activities. With the four steps done in the treatment, the whole life cycle of memes was completed at the same time in the teaching process, namely, assimilation, retention, expression and transmission [16].

\section{Stage 1 Assimilation}

The teacher (meme host) imparted language memes to his students (new meme hosts) through some teaching materials so that language memes could arouse students' interests and attention, especially strong memes and memeplexes. Also, the teacher instructed students to categorize language memes. Students should add or delete something from their textbooks and teaching materials to form their own EFL writing meme pools. Meanwhile, the teacher was supposed to use enough examples to demonstrate different memetic genotypes and phenotypes to strengthen students' mastery of the meanings and functions of language memes.

Language memes includes two kinds: one is words and phrases, the other is patterns, which is subdivided into expressions, sentence structures, paragraph patterns and article formats. There would be three separate teaching programs for developing memes from the lowest level to the most advanced level. The first course was for words and phrase having the same meaning, and words and phrases belonging to the same topic. Examples are nouns which mean opinions (perspective, viewpoint, standing point, attitude, position, proposition, argument etc.), verbs, and so on. The second program was for sentence patterns. As for argumentative writing, the teacher chose such items as strong language memes which include how to express opinions, how to emphasize and how to change a topic, and so on. Meanwhile, words and phrases taught in the first program were reviewed. Formulaic speech is chosen as strong language memes [17] [18]. The last program was for paragraph patterns and article formations. Four different formations of English argu- mentative writing called schema were introduced [19]. Sentence builders were also presented. Model articles were given to the students for better understanding. Again, adding and reciting was indispensable.

\section{Stage 2 Retention}

A meme can become a strong meme on the condition that it infects a new host and enters the host's memory. Four students formed a group to recite and help each other so that their mimetic awareness would be established. The teacher would observe them and check them. Doing like this, students' writing meme pool would be built up.

\section{Stage 3 Expression}

Expression refers to the process in which language memes are picked up from a host's second language meme pool and are transferred as physical forms, so that they can be sensed by new hosts. Some activities were carried out in class. The teacher could instruct students to imitate sentences or paragraphs by practicing the mimetic genotype and the mimetic phenotype [5], they were learning to quote, graft, and transplant sentences [13]. The teacher would ask students to do retelling, paraphrasing, rewriting the text and so on. A deep understanding of language memes would quickly enable students to become new hosts of language memes. Next, the teacher instructed them to write down in class language memes that they might use.

\section{Stage 4 Transmission}

Transmission means transmitting language memes employed by students. Three phases were employed to complete transmission of memes. Firstly, teacher returned them their writings without scoring, whereas strong language memes as well as grammatical errors were underlined. Secondly, the teacher transmitted strong language memes and the fitness of these memes with an emphasis on the format of argumentative writing. Thirdly, students discussed their work with each other, and then rewrote them after class. The teacher graded their second drafts. That is completion of the whole life cycle of memes. The complete teaching process is illustrated in Figure 1.

\section{DATA ANALYSIS AND DISCUSSION}

All the data obtained in this study were processed by Statistical Package for the Social Science 13.0.

\subsection{Results of the pre-test}

We compared their English proficiency and overall English writing competence between the two classes.

From Table 1 and Table 2, we can see that the experimental class and the control class show an insignificant difference in both English proficiency $(p=.355>.05)$ and overall English writing competence $(p=.343>.05)$. 


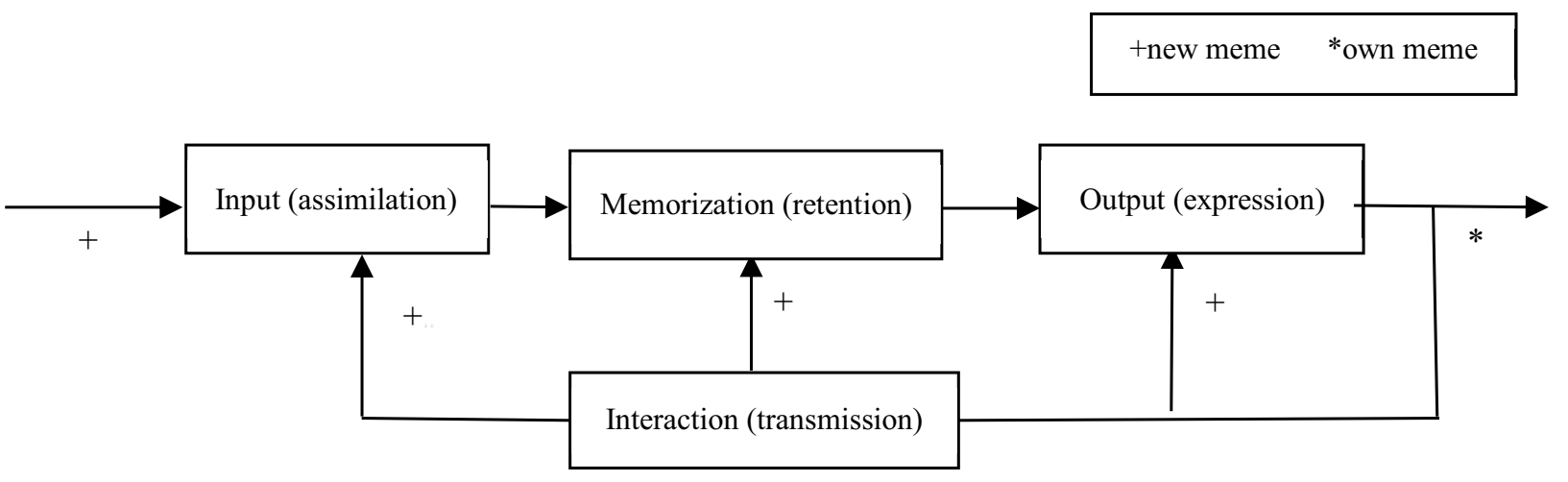

Figure 1. A revised procedure of memetic development in College English writing based on Yang [14]

Table 1. Independent Samples T-Test of college entrance examination

\begin{tabular}{lllllllll}
\hline & Group & $\mathrm{N}$ & Mean & Std. Deviation & Std. Error & $\mathrm{F}$ & $\mathrm{t}$ & Sig. (2-tailed) \\
\cline { 2 - 9 } College entrance & $\mathrm{C}$ & 52 & 88.4038 & 17.83614 & 2.47343 & 1.586 & -.930 & .355 \\
Examination & $\mathrm{E}$ & 52 & 91.3654 & 14.47652 & 2.00753 & & -.930 & .355 \\
\hline
\end{tabular}

Table 2. Independent Samples T-Test of the scores in the pre-test between the classes (Independent Samples T-Test)

\begin{tabular}{lllllllll}
\hline \multirow{4}{*}{ Pre-test } & Group & $\mathrm{N}$ & Mean & Std. Deviation & Std. Error & $\mathrm{F}$ & $\mathrm{t}$ & Sig. (2-tailed) \\
\cline { 2 - 9 } & $\mathrm{C}$ & 52 & 4.4423 & 2.83821 & .39359 & 2.279 & -.952 & .343 \\
& $\mathrm{E}$ & 52 & 4.9423 & 2.50813 & .34782 & & -.952 & .343 \\
\hline
\end{tabular}

Table 3. The Independent Samples T-Test of the scores of post-test between the classes (Independent Samples T-Test)

\begin{tabular}{lllllllll}
\hline \multirow{5}{*}{ Pre-test } & Group & $\mathrm{N}$ & Mean & Std. Deviation & Std. Error & $\mathrm{F}$ & $\mathrm{t}$ & \multicolumn{2}{c}{ Sig. (2-tailed) } \\
\cline { 2 - 9 } & $\mathrm{C}$ & 52 & 6.4808 & 3.05178 & .42321 & .017 & -4.705 & .000 \\
& $\mathrm{E}$ & 52 & 9.3654 & 3.19944 & .44368 & & -4.705 & .000 \\
\hline
\end{tabular}

\subsection{Comparison of the scores of their English writing in the post-test between the two classes}

Table 3 reveals that there does exist significant differences between the two classes. The mean of the post-writing in the experimental class $(9.365)$ is much higher than that of the control class (6.480), the gap (2.88) is widened compared with that in the pre-test $(0.5)$. The significance of $t$-value is $-4.705, p=0.000$ $(<0.05)$, showing that the difference between the two classes is significant (the difference is significant at the level of 0.01). The Std. in the experimental class (3.199) is nearly the same as that of the controlled class (3.051), which means the scores in the two classes are equally deviant from the central point in the distribution. That is to say, treatment does not cause deviance away from the central point. The experimental class achieved significant progress after treatment. What results in the remarkable difference?

Different teaching methods contributed to the difference between the two classes. In the experimental class, the whole life cycle of memes was completed. The teacher imparted language memes to the students in the assimilation stage, thus, they would become conscious of memes appearing in language input; also, they were required to recite the memes they had learned, thus their mimetic writing pools were formed. In the stage of expression, activities were fulfilled to ensure that students could apply those language memes to their essays. Most importantly, students had chances to interact and learn from others in the course of transmission, they were imitating appropriate ways to express their thoughts, which was virtually transmitting language memes. Awareness of using language memes took shape. Hence, after reproduction of an essay, language memes were transmitted, while those frequently used language memes became strong language memes. In the completion of memetic life circle, students' awareness of using language memes was strengthened with the accumulation of vocabulary, formulaic chunks, and patterns. With time going by, it can further students' overall writing proficiency. The result confirms the fact that recitation input contributes to the development of Chinese college students' L2 writing proficiency [20]. As for the control class, the traditional method went through the whole writing process, no such kinds of activities were seen to teach them to express their thoughts appropriately. Most of them were unaware of using language memes in their 
writing. A few of them may employ several language memes in their compositions, not because they have gained an awareness of using language memes, but because language memes exist, and human beings are gifted with imitation.

\subsection{The Independent Samples Test of the numbers of language memes employed by the two classes}

As is apparent from Table 4, the numbers of language memes employed by the students in the two classes show significant differences. Students in the control class employ language memes on the average of 4.884 , whereas the mean of that used by the experimental class is 6.230 , the significance of t-value is $0.004(<0.05)$, which means the difference is significant. The experimental class show significant difference after treatment. In other words, the experimental class outperformed the control class in utilizing language memes in their post-test.

\subsection{Correlation ships analysis}

Table 5 indicates that the significance of t-value is $0.000(<0.05)$, meaning the difference is significant. Pearson Correlation shows that the correlation co-efficiency between language memes and the scores of the post-test in the experimental class is 0.660 , which means language memes and the scores of the post-test are highly correlated.

As discussed in 4.2, students' awareness of using language memes is enhanced in the experimental class During the treatment of this research, five complete processes were fulfilled, memetic life circle was repeated again and again, which ensured sufficient language input [21], the accumulation of implicit knowledge and explicit knowledge contributes greatly to the transformation from implicit knowledge to explicit knowledge [22]. Implicit knowledge which is vocabulary, formulaic chunks and patterns enhances learners' language sense. Mimetically, students (vectors) are assimilated. They learn to "express" their opinions by imitation, with the ongoing of the experiment, language memes are spread during the vectors' interaction with each other, and strong memes spread quickly and widely. Imitation and re-writing contribute to the improvement of students' overall writing proficiency, consequently, writings with higher scores have produced, and language memes are replicated and spread in this process.

\subsection{Comparison of language memes used by students in the experimental class}

Table 6 indicates that singular language memes with an average 6.230 were employed by students in the post-test, whereas the mean of memplexes is 2.692 , all of them belong to genotype, no phenotype is employed. It is evident that singular language memes can be easily transmitted; genotype prevails in EFL learners' essay writing. This phenomenon can be explained from the memetic point of view.

Singular memes with forms of words, phrases and formulaic chunks are easily to be recited, imitated by language learners in the writing because of its strong power, such kind of language memes require the least adjustment. These words and phrases will appear immediately in students' writing. Memeplexes are patterns, the schema of paragraphs and passages, EFL learners would like to choose one or two to express their ideas appropriately.

We know mimetic genotype transmission refers to the repetition or complete copying of the original language meme [23]. Memes of genotype have the same meaning, whereas memes of mimetic phenotype have different meanings with the same form. In the mimetic phenotype transmission, the original language memes such as the number of characters, words or lines, or

Table 4. The Independent Samples Test of the language memes in the post-test: Independent Samples Test

\begin{tabular}{lllllllll}
\hline \multirow{5}{*}{ Language memes } & Group & $\mathrm{N}$ & Mean & Std. Deviation & Std. Error & $\mathrm{F}$ & $\mathrm{t}$ & Sig. (2-tailed) \\
\cline { 2 - 9 } & $\mathrm{C}$ & 52 & 4.8846 & 2.07368 & .28757 & 3.867 & -2.928 & .004 \\
& $\mathrm{E}$ & 52 & 6.2308 & 2.58666 & .35870 & & -2.928 & .004 \\
\hline
\end{tabular}

Table 5. Correlation ships between language memes and the scores of the post-test in the experimental class (Correlations)

\begin{tabular}{llll}
\hline & & Post-test & language memes \\
\cline { 2 - 4 } Language memes & Pearson Correlations & $.660^{* *}$ & 1 \\
& Sig. (2-tailed) & .000 & \\
& $\mathrm{~N}$ & 52 & 52 \\
\hline
\end{tabular}

Note: Correlation is significant at the 0.01 level (2-tailed)

Table 6. Singular language memes used in the post-test by students in the experimental class (Group Statistics)

\begin{tabular}{llllllll}
\hline & Group & $\mathrm{N}$ & Mean & Singular memes & Memeplex & Genotype & Phenotype \\
\hline Post-test & E & 52 & 6.23 & 2.692 & 6.23 & 6.23 & 0 \\
\hline
\end{tabular}


their form of sequence, are changed based on different pragmatic contexts. Although language memes such as the idioms, sayings, proverbs, or poems, allusions and so on have high fecundity [7], sometimes their forms and contents are hard to meet the needs or situations of the changing world. It is self-evident that phenotype can be easily imitated and transmitted by native speakers, but the case is totally different when it comes to EFL learners. Using mimetic phenotype requires mastery of a foreign language and flexible usage, which goes beyond college freshmen.

\section{FINDINGS AND CONCLUSION}

The study generates the following findings. Firstly, students instructed by the framework of teaching writing with memetics obtain an obvious improvement in their overall writing proficiency, compared with those who are instructed by the traditional method, their awareness of using memes is greatly enhanced, and language memes is significantly correlated to the students' performance in post-test writing. Secondly, applying memetics to the teaching of College English Writing with a combination of the Process Approach is feasible, and the framework consists of four parts: input, memorization, output and interaction. Each of them is necessary and interdependent. Finally, singular memes are more easily transmitted and imitated by language learners in their writing, while mimetic genotype is more likely to spread than the phenotype.

Of course, there are some limitations in this study. The focus of this thesis is of argumentative writing. Room is left for its long-term effect and its effectiveness in the teaching of other styles.

\section{ACKNOWLEDGEMENT}

This paper is sponsored by a key project of teaching research item named of $A$ case study on the relationships between language memes and college students' English writing proficiency in Wuhan University of Technology Huaxia College No.1415).

\section{REFERENCES}

[1] Dawkins, R. 1976. The Selfish Gene. New York: Oxford University Press, pp.203.

[2] Dawkins, R. 1986. The Extended Phenotype. Oxford: Oxford University Press, pp.158.
[3] Blackmore, S. 1999. The Meme Machine. Oxford: Oxford University Press, pp.228-230.

[4] Blackmore, S. 2001. Evolution and memes: The human brain as a selective imitation device. Cybernetics and Systems Analysis, pp.225.

[5] He Ziran. 2007. Linguistic memes and their rhetoric effects. Foreign Language Research, 101(3): 51-56.

[6] Xie Chaoqun \& He Ziran. 2007. Brief introduction of language memes. Modern Foreign Languages (Quarterly), 30(1): 31-35.

[7] He Ziran. 2005. Meme in language. Language Science, 19(6): 58-63.

[8] He Ziran \& He Xuelin. 2003. Memetics and social usage of language. Modern Foreign Language (Quarterly). 26(2): 201-209.

[9] Wang Bin. 2004. Memes and translation. Foreign Language Research, 85(3): 38-44.

[10] Wang Chunlei. 2008. Review of meme research, Journal of Jimei University, 11(3): 63.

[11] Zhang Zaixin, et al. 1995. Main issues in college English writing in China. Foreign Language Teaching and Research, 38(2): 43-50.

[12] Wang Wenyu \& Wang Lifei. 2004. Research of second language writing: Review and expectation of the past ten years, Foreign Language World.

[13] Chen Linxia \& He Ziran. 2006. Analysis of memes in language, Foreign Language Teaching and Research, 38(2): 108-114.

[14] Yang Lu. 2007. Evaluating the Feasibility of Applying Memetics in ESL Writing Teaching, Hunan: Hunan University, pp: 56-58.

[15] Carrell, PL, Content and Formal Schemata in ESL reading, TESOL Quarterly, Vol. 21, pp. 461- 482, 1987.

[16] Henrik Bjarneskans, Bjarne Grnevik and Anders Sandberg. The Life Circle of Memes.

http://www.aleph.se/Trans/Cultural/Memetics/memecycl e.html-60k-.1997.

[17] Wary, Alison. 2000. Formulaic sequences in second language teaching: Principle and practice, Applied Linguistics, 21(4): 463.

[18] Weinert, Regina. 1995. The role of formulaic language in second language acquisition: A review, Applied Linguistics, 16(2): 180-205.

[19] Guy R. Lefrancois. 2004. Theories of Human Learning, Shanghai: Foreign Language Teaching and Research Press, pp.235.

[20] Deng Liming \& Wang Xiangyun, 2007. A study on the actual efficacy of recitation input for the development of Chinese college students' L2 writing proficiency, Foreign Language Education, 28(4): 54-55.

[21] Krashen, S.D. 1985. The Input Hypothesis: Issues and Implications, London: Longman Group Limited, pp. 175-182,

[22] Cao Yilu. 1999. Should borrow the teaching experience from Chinese traditional language teaching, Foreign Language World, 64(2): 16-19.

[23] Chen Linxia. 2008. Memetics and the teaching of college English writing, Foreign Language Research, 140(1): 88-89. 